\title{
Isolated cc-TGA in an adult presenting for the first time with a complete heart block managed by dual-chamber pacemaker implantation
}

Pranab Jyoti Bhattacharyya, Sharat Vijapur

Department of Cardiology, Gauhati Medical College, Guwahati, Assam, India

\section{Correspondence to}

Dr Pranab Jyoti Bhattacharyya, drpranabguwahati@gmail.com

Accepted 14 June 2014

\section{DESCRIPTION}

A 32-year-old male patient presented with sudden onset of altered sensorium and vomiting preceded by respiratory distress of $5 \mathrm{~h}$ duration. On general physical examination his pulse rate was $40 / \mathrm{min}$, blood pressure $140 / 60 \mathrm{~mm} \mathrm{Hg}$ and prominent cannon 'a' wave in jugular venous pressure (JVP). Cardiovascular examination revealed an apex beat located in the left fifth intercostal space (ICS) inside the mid-clavicular line, palpable second sound $\left(\mathrm{A}_{2}\right)$ in the second left ICS, variable $\mathrm{S}_{1}$, single and accentuated $S_{2}\left(A_{2}\right)$ and a grade $3 / 6$ pan systolic murmur in the apical area. His ECG showed a complete heart block (CHB) with a ventricular rate of $40 / \mathrm{min}$ (figure 1). An emergency temporary pacemaker was implanted via the right transfemoral route in view of symptomatic $\mathrm{CHB}$ (figure 2).

Clinical, ECG and two-dimensional transthoracic echocardiographic findings (figure 3) were

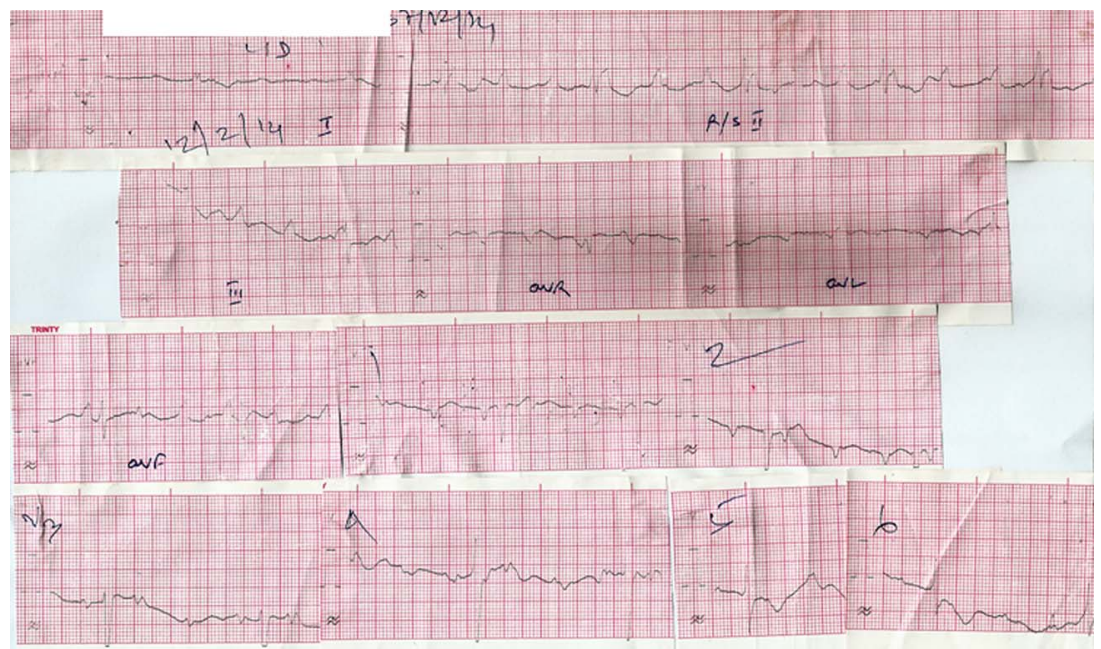

Figure 1 ECG showing a complete heart block; note the prominent Q waves present in the right precordial leads and absent in the left.

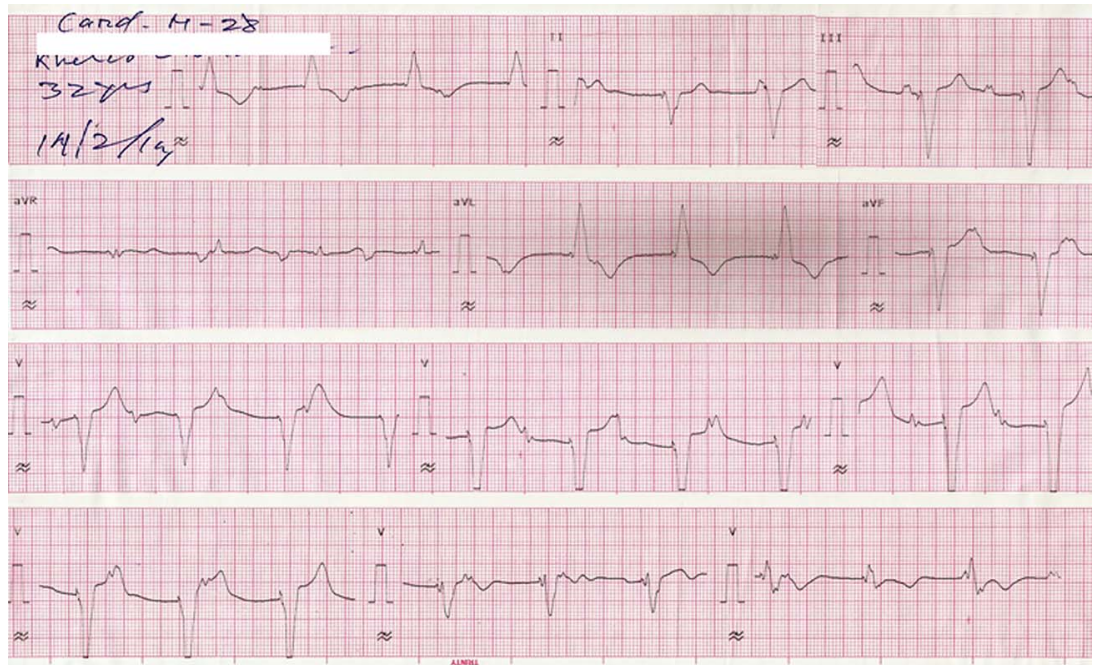

Figure 2 ECG after temporary pacemaker implantation showing a ventricular paced rhythm. 

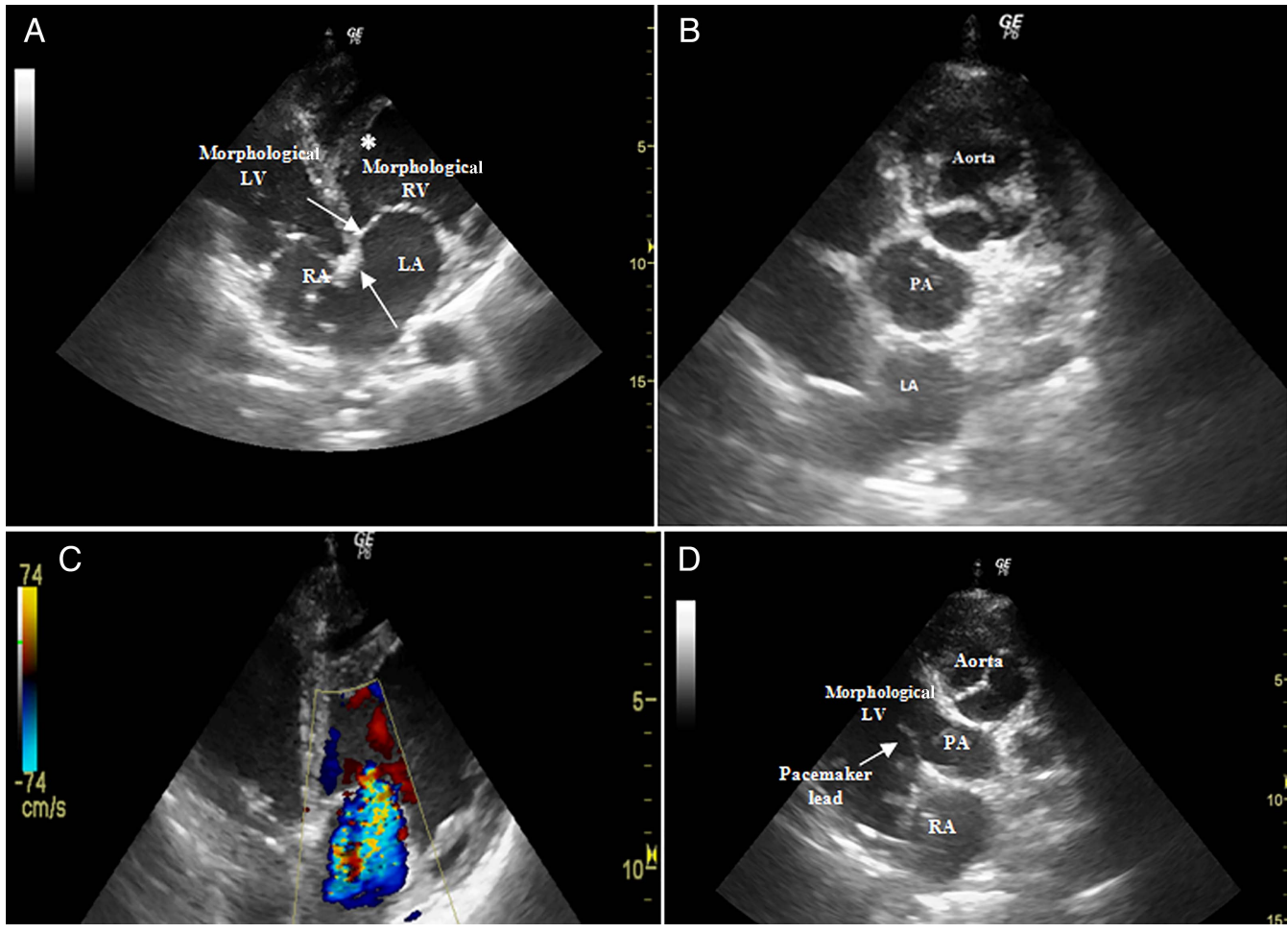

Figure 3 (A) A two-dimensional apical four-chamber view. Note the anatomy of the internal cardiac crux (arrow). The septal insertion of the left atrioventricular (AV) valve is slightly apical to that of the right AV valve (arrow). This relation is the anatomic hallmark of the congenitally corrected transposition of the great arteries and the most reliable echocardiographic finding for identifying the morphology of the ventricle associated with the AV valve and discordant AV connections. The moderator band $\left(^{*}\right)$ can also be seen within the left ventricle (LV). (B) In the short-axis view, the aortic and pulmonic valves are seen in cross section with the aortic valve located anterior and to the left of the pulmonic valve. (C) Apical four chamber showing moderate left AV valve regurgitation. (D) The pulmonary artery (PA) arises from the morphological LV; note the pacemaker lead in situ (right atrium (RA) to morphological LV; LA, left atrium; RV, right ventricle).

consistent with a diagnosis of isolated congenitally corrected transposition of the great arteries (cc-TGA). A transvenous dual-chamber permanent pacemaker (Medtronic Relia DDDR with Search $\mathrm{AV}+$ ) was implanted via the left subclavian vein (figure 4). Satisfactory pacing parameters were achieved in the apical position. The Search $\mathrm{AV}+$ algorithm incorporated in this model was preferred for our patient because of the moderate systemic ventricular dysfunction $(40 \%$ ejection fraction (EF)). This algorithm automatically extends the atrioventricular (AV) delay and uncovers intrinsic conduction, thereby minimising unnecessary ventricular pacing, and lowers the risk of heart failure admissions and atrial fibrillation in anatomically normal hearts. The patient was discharged in a haemodynamically stable condition on the 10th day with eplerenone $25 \mathrm{mg}$, ramipril $2.5 \mathrm{mg}$ and carvedilol $3.125 \mathrm{mg}$ twice daily treatment.

In view of the $40 \% \mathrm{EF}$ in our patient, biventricular pacemaker or cardiac resynchronisation therapy (CRT) could have been an option, but until now specific CRT criteria for such patients are unavailable and evidence of benefit from CRT for adult patients with a systemic right ventricle (RV) is limited. Apart from financial constraints, de novo CRT was not considered in our patient as he had a conventional indication for antibradycardia pacing associated with cc-TGA with moderate
Figure 4 The patient underwent a dual-chamber pacemaker implantation for a complete heart block with active fixation lead (circle) for the right-sided morphological left ventricle. Active fixation electrodes are preferred rather than tined leads for better lead stability because of the lack of apical trabeculations in the right-sided morphological left ventricle.
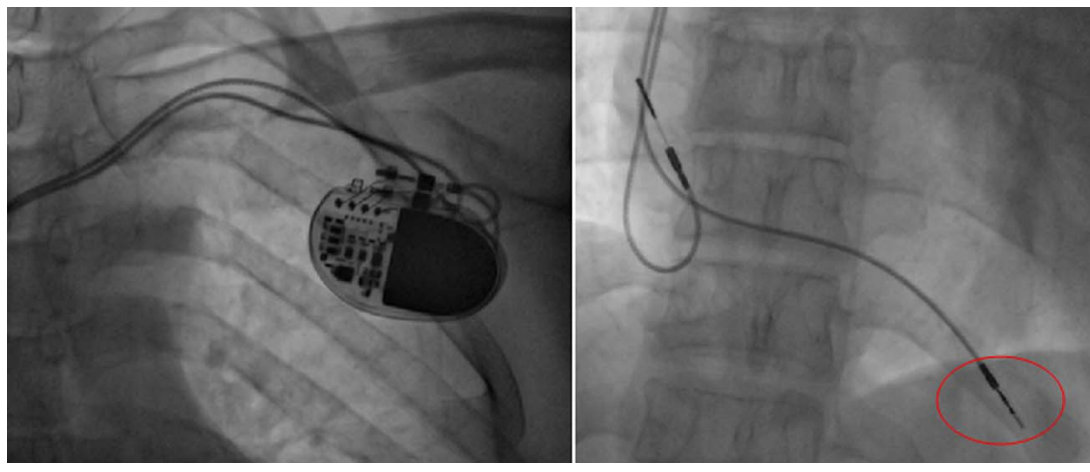


\section{Learning points}

- Congenitally corrected transposition of the great arteries (cc-TGA) is a rare anomaly $(<1 \%$ of all congenital heart disease) characterised by atrioventricular (AV) and ventriculoarterial discordance and by a physiologically corrected circulation with a morphological right ventricle supporting the systemic circulation.

- Associated cardiac defects are common and encountered in up to $95 \%$ of patients; the most common defects are ventricular septal defect (membranous or muscular) $~ 80 \%$, pulmonic stenosis $\sim 70 \%$ and tricuspid valve abnormalities (usually Ebstein's anomaly) 33\%; isolated cc-TGA (without associated cardiac defects) is an exception seen in only $5 \%$, and unoperated adult survival is seen only in isolated CC-TGA.

- A complete heart block (CHB) may be present from birth (in $\sim 10 \%$ ) and develop in $2 \%$ of patients per year. ${ }^{2}$

- Major problems associated with adult survivors of cc-TGA are $\mathrm{CHB}$, systemic (tricuspid) AV valve regurgitation, systemic (right) ventricular dysfunction and atrial tachyarrhythmias.

- The role of medical therapy (ACE inhibitors, $\beta$-blockers, aldosterone antagonists) for systemic ventricular dysfunction has not been demonstrated conclusively. Tricuspid valve replacement is preferred for significant systemic AV valve regurgitation, but the reoperation rate is high (15-25\%). Data of double switch procedure in adults are lacking. Cardiac transplantation may be considered for deteriorating systemic ventricular function despite aggressive medical therapy. ${ }^{3}$ systemic ventricular dysfunction and in New York Heart Association (NYHA) class I without a left bundle-branch block and the quality of evidence favouring CRT implantation in such subset of patients is low. Therefore, a strategy of initial conventional antibradycardia pacing, with later upgrade in case of worsening symptoms, seemed reasonable in our patient. Also, when pacing is inevitable, pacing from alternative right ventricular sites in anatomically normal hearts have shown better preservation of left ventricular EF compared to RV apical pacing, especially in those with baseline $\mathrm{EF}<45 \%$. Whether this is true for cc-TGA hearts is not well established. This case highlights the fact that isolated cc-TGA, although rare, may remain asymptomatic and undetected in childhood and may be diagnosed for the first time in adulthood when they present with $\mathrm{CHB}$ warranting appropriate pacemaker implantation.

Contributors PJB has contributed to the drafting and finalisation of the document apart from diagnosis and treatment of the patient. SV has helped in diagnosis and patient care.

Competing interests None.

Patient consent Obtained.

Provenance and peer review Not commissioned; externally peer reviewed.

\section{REFERENCES}

1 Lundstrom U, Bull C, Wyse RK, et al. The natural and "unnatural" history of congenitally corrected transposition. Am J Cardiol 1990;65:1222-99.

2 Huhta JC, Maloney JD, Ritter DG, et al. Complete atrioventricular block in patients with atrioventricular discordance. Circulation 1983;67:1374-7.

3 Webb GD, Smallhorn JF, Therrien J, et al. Congenital heart disease. In: Bonow RO, Mann DL, Zipes DP, Libby P, eds. Braunwald's heart disease: a textbook of cardiovascular medicine. Philadelphia, PA: Elsevier Saunders Ninth International Edition 2012:1411-67.

Copyright 2014 BMJ Publishing Group. All rights reserved. For permission to reuse any of this content visit http://group.bmj.com/group/rights-licensing/permissions.

BMJ Case Report Fellows may re-use this article for personal use and teaching without any further permission.

Become a Fellow of BMJ Case Reports today and you can:

- Submit as many cases as you like

- Enjoy fast sympathetic peer review and rapid publication of accepted articles

- Access all the published articles

- Re-use any of the published material for personal use and teaching without further permission

For information on Institutional Fellowships contact consortiasales@bmjgroup.com

Visit casereports.bmj.com for more articles like this and to become a Fellow 